\title{
Japan's research institutes face cuts in maintenance budgets
}

[TOKYO] Japan's structural reform of its national finances has left many of its research institutes facing substantial cuts in their maintenance budgets - even though the country is continuing to increase its spending on science and technology as part of a government plan to double spending on science between 1996 and 2001.

Although the overall budget for the 1998 fiscal year, beginning on 1 April, sees the smallest increase in recent years at 0.4 per cent, funding for science and technology has won a 4.9 per cent increase (see Nature 391, 111; 1998). The Ministry for Education, Science, Sports and Culture (Monbusho), whose overall budget fell by 0.4 per cent, appeared to maintain its support for research by increasing its science and technology spending by 5.1 per cent.

In practice, however, research institutes under Monbusho expect a difficult year ahead. The budget for the next fiscal year, which was approved by the Diet (Japan's parliament) this month, includes a 15 per cent cut in maintenance budgets. This is a result of the government's efforts to reform Japan's ailing financial system under the newly formed Fiscal Structural Reform Act.

Most of the large research institutes set up by Monbusho for joint university use, such as the National Astronomical Observatory (NAO), the Institute for Space and Astronautical Science (ISAS) and the National Institute of Genetics (NIG), will face such cuts, even though their overall research budgets remain the same as last year.

At NAO, which provides advanced observational facilities to researchers throughout Japan, the cuts would affect general maintenance of the facility, such as operation of the telescopes, and paying expenses and electricitybills.

Although the observatory has received substantial funding for its new projects, such as the construction of 'Subaru', the world's largest optical-infrared telescope, due to begin operation this summer in Hawaii, the budget cut would make it difficult to carry out new research at NAO.

"The situation is ironic - possessing all this sophisticated equipment will mean very little if we can't switch it on," says Keiichi Kodaira, NAO's director. "Without being able to maintain the facility, it would be impossible to carry out internationally competitive research."

Most institutes have started to plan costcutting measures for the next fiscal year, trying to minimize damage to their research projects. "We are still trying to plan various

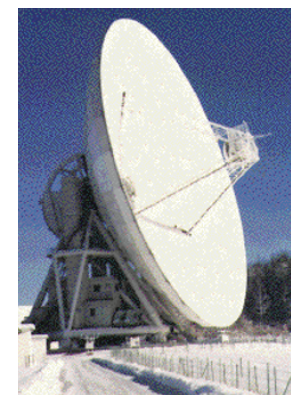

Cold prospects: radio telescopes may lack enough funds to run. measures for overcoming this difficulty," says NIG's director, Yoshiki Hotta. According to Hotta, the budget cut would mainly affect computer maintenance, species preservation and feeding of laboratory animals.

Officials at ISAS expect that the 15 per cent cut would affect basic research on the development of satellite launch vehicles. Atsuhiro Nishida, director of ISAS, is particularly worried that the cut would jeopardize future research, especially if all efforts are directed towards saving current research projects.

The problem lies with the government's general account, which supplies the national institutes' maintenance budgets, and which has been cut across the board to meet the government's restructuring plan. Under the plan, government deficits must be reduced from the current level of 5.9 per cent to 3 per cent of gross domestic product.

Various government-related science ministries and agencies have managed to maintain growth in their overall budgets by expanding special accounts that operate separately from the general account. But, in the case of the national institutes, these budgets cannot be allocated to maintenance costs.

According to Nishida, the funding system is badly designed for supporting long-term research projects such as those being done at ISAS. "If the government is to fully implement the 'five-year plan' to support scientific research, they will have to create a system under which scientists are given an environment to carry out competitive research," says Kodaira.

AsakoSaegusa

\section{Green light for US spallation source}

[WASHIngton] US Vice-President Al Gore announced last week that the Clinton administration will include \$157 million in its budget request to Congress for the 1999 fiscal year (which begins on 1 October 1998) to begin building a new spallation source for neutrons at the Oak Ridge National Laboratory in Tennessee.

The Department of Energy (DOE), which operates Oak Ridge, has been planning to build the $\$ 1.3$ billion facility for some time, but the project has until now received funding only for the planning stages. When completed in 2005, it will be the most powerful source of pulsed neutrons in the world, and will help scientists to refine their characterizations of materials and biological structures.

Gore, a former senator and congressman from Tennessee, said the new facility "will help us to reclaim America's position as the world leader in a technology we invented". At present, world leadership in spallation neutron production is filled by Britain's ISIS, and France is home to the most productive reactor source of neutrons for research.

The spallation project was conceived as a form of consolation prize for Oak Ridge, which three years ago lost its Advanced Neutron Source, a proposed $\$ 3$ billion research reactor to have been fuelled by highly enriched uranium, because of tight budgets and concern about nuclear proliferation (see Nature 383, 207; 1996).
Unlike reactors, which produce neutrons through the fission process, spallation sources literally knock neutrons loose from heavy elements such as tungsten, using a stream of high-energy protons from an accelerator. They are largely free from the nuclear waste and other environmental concerns associated with reactors.

Materials researchers, structural biologists and other scientists from universities, national laboratories and industry are lining up to use the DOE's three other neutron sources: Oak Ridge's High Flux Isotope Reactor, the Intense Pulsed Neutron Source at Argonne National Laboratory, and Los Alamos National Laboratory's Neutron Science Center. The Energy Secretary, Federico Peña, told the Oak Ridge audience that about 800 researchers use these neutron sources each year, but many more would like to.

The DOE's other major neutron source, the High Flux Beam Reactor at Brookhaven National Laboratory, has sat idle since the discovery of a tritium leak from the reactor's spent fuel basin more than a year ago (see Nature 388, 503; 1997). Peña recently announced that he had delayed a decision on whether to restart the Brookhaven facility until after the congressional elections next November. Two Republicans from New York, Senator Alfonse D'Amato and Michael Forbes, have announced their opposition to reopening the reactor.

Dave Kramer 